7. Hadaway LC. Flushing to reduce central catheter occlusion. Nursing 2000;30:74.

8. Fernandez RS, Griffiths RD, Murie P. Peripheral venous catheters: a review of current practices. J Infus Nurs 2003;26:388-392.

\section{The 2009 H1N1 Influenza A Pandemic and Hand Hygiene Practices in a Hospital in the South of Brazil}

To the Editor-Brazil was severely affected by the 2009 H1N1 influenza A pandemic. The pandemic was most felt in the southern states ( 8.6 cases per 100,000 inhabitants), a temperate zone region bordering Argentina, Uruguay, and Paraguay. ${ }^{1}$

Hospital de Clínicas de Porto Alegre is a 790-bed, university-affiliated tertiary care hospital located in the southernmost state of Brazil. By late July, the hospital had organized its strategy to respond to the pandemic: suspected patients were seen in a distinct unit, a unique ward and intensive care unit (ICU) were used for inpatient care, and staff training about virus transmission and the benefits of hand hygiene in preventing dissemination was reinforced. ${ }^{2,3}$

From June through September (winter season) 2009, a total of 548 inpatients were evaluated for $2009 \mathrm{H} 1 \mathrm{~N} 1$ influenza A infection. Among 154 patients tested for the presence of the $\mathrm{H} 1 \mathrm{~N} 1$ virus with real-time polymerase chain reaction assay, $75(48.7 \%)$ had positive results.

Adherence to hand hygiene has been monitored by means of direct observation in our ICU since 2006. The ICU staff are aware that observation occurs but cannot detect it or predict when it will occur.

From July 2006 through March 2010, the hand-washing technique of physicians, nurses, and technicians was observed daily for 20-30-minute intervals during 5 morning, 5 afternoon, and 3 night shifts, during all 5 weekdays. Weekends were excluded from the observation schedule. In addition, the consumption of alcohol-based hand rub was measured in milliliters per 100 patient-days.

The 1-sample Student $t$ test was used to compare the mean rates of adherence to hand-washing. One-way analysis of variance with the 2-sided Tukey test for multiple comparisons was performed to compare mean differences in adherence between groups of professionals. Time-series segmented regression analysis was used to determine significant changes in level (immediate) and trend (slope) of adherence to handwashing, before (July 2006 through May 2009) and during and after (June 2009 through March 2010) the 2009 H1N1 influenza A season in Brazil. ${ }^{4}$

From July 2006 through March 2010,21,438 opportunities for hand hygiene were observed. The overall mean adherence rate was $57.1 \%$ (range, $46.2 \%-69.7 \%$ ). The mean rate of adherence to hand hygiene was $76.6 \%$ (range, 59.5-96.6\%) for nurses, compared with $54.1 \%$ (range, $43.7 \%-69.6 \%$ ) for technicians $(P<.001)$ and $44.2 \%$ (range, $23.0 \%-70.6 \%)$ for physicians $(P<.001)$.

Segmented regression analysis revealed no difference in the observed rate of adherence before the $2009 \mathrm{H} 1 \mathrm{~N} 1$ influenza A pandemic, compared with during and after the pandemic (slope change from 0.07 to $0.24 ; P=.44$ ). The use of alcoholbased hand rub from wall dispensers showed no significant difference in immediate consumption in the ICU (level change from 0.83 to $0.28 ; P=.17$ ) but a significant decrease thereafter (slope change from 0.33 to $-0.38 ; P=.05$ ). The use of hand rub from wall dispensers throughout the entire hospital showed a transient significant increase in consumption (level change from 0.59 to $0.64 ; P<.001$ ) and a slope decrease thereafter (trend change from 0.59 to $-0.36 ; P=$ .02) (Figure 1).

The mean rate of adherence to hand hygiene before patient contact was $44.5 \%$ (range, $23.0 \%-66.7 \%$ ) and after patient contact was $74.9 \%$ (range, $61.8 \%-87.5 \%)(P<.001$ ). The segmented regression model revealed no change in the rate of adherence before and after patient contact in relation to the $2009 \mathrm{H} 1 \mathrm{~N} 1$ influenza A pandemic.

Despite the increase in consumption of alcohol-based hand rub during the peak period of the pandemic, this behavior was not sustained through the subsequent months. The numerous media reports related to $2009 \mathrm{H} 1 \mathrm{~N} 1$ influenza $\mathrm{A}$ had an effect in terms of dissemination of hand-washing practices. As reported by the Brazilian Ministry of Health, $89 \%$ of people surveyed were informed about the pandemic by television. ${ }^{5}$ However, the media most influenced changes in social behavior, and importantly, these changes, as manifested in the hand hygiene practices of healthcare workers, were transient, as we have shown. A change in social behavior does not necessarily lead to a long-term change in hand hygiene practices in hospitals.

Inherent community and home hand-washing practices are a predictor of in-hospital hand-washing behavior, ${ }^{6-8}$ which means that, in hospitals, hand hygiene will be performed as one learns at home: one cleans one's hands after they become visibly soiled-in other words, an action to protect oneself. This was the message people received from television: "protect yourself," not "protect your patient." This is why we would not expect a significant change in healthcare worker behavior in hospitals. Direct observation at our hospital revealed no change in hand-washing practices in relation to the World Health Organization (WHO) 5 moments. The mean rate of adherence before patient contact (ie, to protect the patient) was significantly lower than the rate of adherence after patient contact (ie, to protect the healthcare worker), and this scenario did not change after the beginning of the pandemic.

Our data reflect the limitations related to both methods of ascertaining adherence to hand hygiene. The observation 


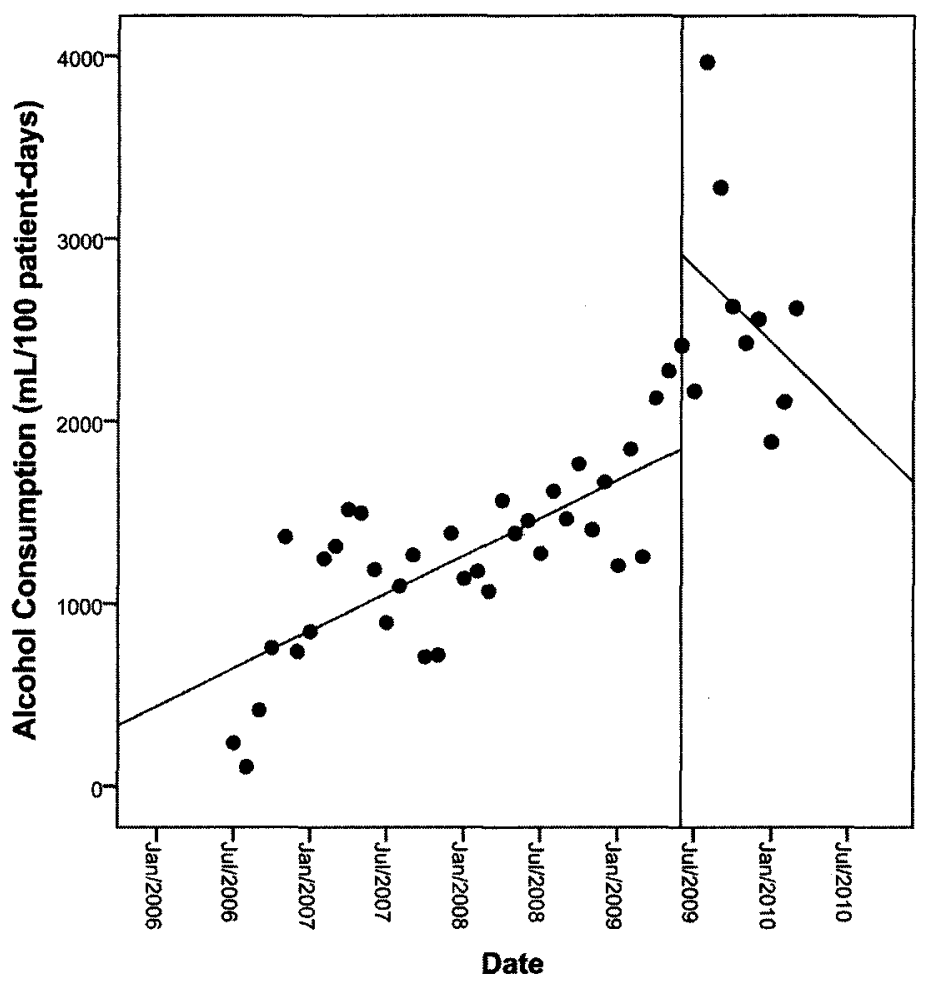

FIGURE 1. Consumption of alcohol-based hand rub throughout the entire hospital in milliliters per 100 patient-days, before, during, and after the $2009 \mathrm{H} 1 \mathrm{~N} 1$ influenza A pandemic in Brazil.

method, despite being the gold standard, has problems related to the number of observations, and although a large number of moments were observed at our hospital, our observation schedule covered only 1 hour of a 24-hour day. On the other hand, measurement of the consumption of alcohol-based hand rub cannot predict behavior in relation to the WHO 5 moments and cannot be stratified according to professional category, despite being accurate in terms of 24-hour consumption. Use of hand rub unrelated to patient care or during opportunities not covered by the WHO 5 moments could have had an effect on the significant increase in consumption of hand rub from wall dispensers.

In summary, the $2009 \mathrm{H} 1 \mathrm{~N} 1$ influenza A media campaigns to prevent transmission were not sufficient to change healthcare worker behavior or to sustain a change through the months after the pandemic inside the hospital. Although there was an increase in the use of alcohol-based hand rub, this was not accompanied by a change in behavior. More focused educational programs addressing the WHO 5 moments should be implemented to improve hand-washing practices in hospitals during the next pandemic.

\section{ACKNOWLEDGMENTS}

Financial support. We thank the Fundo de Incentivo a Pesquisa e Eventos (FIPE), Hospital de Clínicas de Porto Alegre, Brazil, for partial support of this study.
Potential conflicts of interest. All authors report no conflicts of interest relevant to this article.

Rodrigo Pires dos Santos, MD;

Loriane Rita Konkewicz, ICP, Msc; Fabiano Nagel, MD; Thiago Lisboa, MD; Thalita Jacoby, PharmD, Msc;

Sandra Ludwig Gastal, MD;

Nádia Mora Kuplich, ICP, Msc;

Guilherme Sander, MD, PhD; Márcia Pires, ICP; Carem Gorniak Lovatto, ICP

From the Hospital Infection Control Committee, Hospital de Clínicas de Porto Alegre, Porto Alegre, Rio Grande do Sul, Brazil (all authors).

Address reprint requests to Rodrigo Pires dos Santos, MD, Rua Ramiro Barcelos 2350, CEP: 90035-903, Porto Alegre-RS, Brazil (rpsantos@hcpa .ufrgs.br).

Infect Control Hosp Epidemiol 2010; 31(12):1313-1315

(C) 2010 by The Society for Healthcare Epidemiology of America. All rights reserved. 0899-823X/2010/3112-0023\$15.00. DOI: 10.1086/657582

\section{REFERENCES}

1. Oliveira W, Carmo E, Penna G, et al; Surveillance Team for the pandemic influenza A (H1N1) 2009 in the Ministry of Health. Pandemic H1N1 influenza in Brazil: analysis of the first 34,506 notified cases of influenza-like illness with severe acute respiratory infection (SARI). Euro Surveill 2009;14(42):pii = 19362. http://www.eurosurveillance.org/ViewArticle 
.aspx?ArticleId $=19362$. Published October 22, 2009. Accessed March 22, 2010.

2. Cowling BJ, Chan $\mathrm{KH}$, Fang VJ, et al. Facemasks and hand hygiene to prevent influenza transmission in households: a randomized trial. Ann Intern Med 2009;151:437-446.

3. Aiello AE, Murray GF, Perez V, et al. Mask use, hand hygiene, and seasonal influenza-like illness among young adults: a randomized intervention trial. $J$ Infect Dis 2010;201:491-498.

4. Zhang F, Wagner AK, Soumerai SB, Ross-Degnan D. Methods for estimating confidence intervals in interrupted time series analyses of health interventions. J Clin Epidemiol 2009;62:143-148.

5. Pesquisa para comunicação de resultados. Influenza A (H1N1). Ministério da Saúde do Brasil website. http://portal.saude.gov.br/portal/arquivos/ pdf/pesquisa_influenza0903.pdf. Published March 2010. Accessed April 28, 2010.

6. Whitby M, Pessoa-Silva CL, McLaws ML, et al. Behavioural considerations for hand hygiene practices: the basic building blocks. J Hosp Infect 2007;65; $1-8$.

7. Whitby M, McLaws ML, Ross MW. Why healthcare workers don't wash their hands: a behavioral explanation. Infect Control Hosp Epidemiol 2006; 27:484-492.

8. Mitka M. Hand washing, a key anti-flu strategy, often neglected by health care workers. JAMA 2009;302:1850-1851. 